\title{
The Influence of Welding Angle for the Joints Mechanical Properties with MSHS Vertical Rods
}

\author{
Liu Haodong* \\ Aerial Mechanical Department \\ Naval Aeronautical and Astronautical University \\ Qingdao, China \\ e-mail:mdlhd@sina.com \\ * Corresponding Author \\ Hu Fangyou \\ Aerial Mechanical Department \\ Naval Aeronautical and Astronautical University \\ Qingdao, China \\ e-mail: navy_hd@163.com
}

\author{
Cui Aiyong \\ Aerial Mechanical Department \\ Naval Aeronautical and Astronautical University \\ Qingdao, China \\ e-mail: cuiaiyonghaijun@ sina.com \\ Wang Xiaofei \\ Department of control \\ Naval Aeronautical and Astronautical University \\ Qingdao, China \\ e-mail: cody05@163.com
}

\begin{abstract}
Manual self-propagating high-temperature synthesis welding attracts many researchers' interest due to the special advantages of which in the field emergency recovery service. The welding technic has a great consuming effect to the joint microstructure and mechanical property when render a vertical welding for the Q235 steel sheet with the SHS rods which its ingredient has been optimized. In this paper, in allusion to the feature of the SHS rod, the effect of the welding angle for the joint microstructure and mechanical property was researched with the metallographic analysis and test of mechanical property. The results show that the adnexed metal ratio of rod, the weld crater of base metal and the tensile-strength of joints will be altered as the change of the welding angle, meanwhile, the pattern of joint microstructure will have a corresponding change either.
\end{abstract}

Keywords-SHS; welding angle; vertical welding; microstructure; mechanical properties

\section{INTRODUCTION}

As a new welding technology manual self-propagating welding (MSHSW) has become a hot topic since the spread of technology research [1-3]. The welding technology was based on self-propagating fusion, which was integration innovation for the traditional welding technology combined with self-propagating high temperature synthesis technique [4,5]. The welding technology have significant advantages such as no need for external energy and equipment, carrying convenient, simple operation and can be used individual, in fast common use and so on, the welding method was an ideal welding technology in emergency repair, and which has a broad application prospect [6].

The welding materials were combustion rods, the high temperature heat source of which comes from combustion synthesis reaction. The base metal was melted by the high temperature heat, and the weld metal comes from the product of the combustion synthesis reaction, the operational approach was similar with manual arc welding. the welding joints have good comprehensive mechanical properties, which tensile strength up to $400 \mathrm{MPa}$ approximately and the bending strength was up to 1126 MPa and impact toughness was up to $32 \mathrm{~J}$, the mechanical properties fully meet the welding joints requirements for both battlefield and field emergency repair [7-10]. The welding technology was a revolutionary change from accompanying service to in-situ maintenance for emergency welding of damaged metal components in the battlefield and field [10].

\section{EXPERIMENTAL MATERIALS AND METHODS}

The specification for general SHS welding rods based on Fe-base which was developed by our organization were $10 \mathrm{~mm}$ in diameter and $160 \mathrm{~mm}$ in length, and the mass fraction of each component in welding rods were shown in table I. The welded specimen materials were industrial Q235 steel, which specifications were $70 \mathrm{~mm} \times 35 \mathrm{~mm} \times 3$ $\mathrm{mm}$, which chemical compositions were shown in table II [11].

TABLE I. THE CHEMICAL COMPositions OF THE COMBUSTION WELDING ROD ( W\% )

$\mathrm{CuO}+\mathrm{Al} \mathrm{Fe}_{2} \mathrm{O}_{3}+\mathrm{Al}$ Thinner $\mathrm{Ni}$ MnFe $\mathrm{FeSi}$ Other

$\begin{array}{lllllll}48.7 & 23.5 & 14.7 & 5.9 & 2.5 & 2.6 & 2.1\end{array}$

TABLE II. Chemical Compositions OF BASE Metal

\begin{tabular}{cccccccc}
\hline \multirow{2}{*}{ Grade } & \multirow{2}{*}{ Degree } & \multicolumn{5}{c}{ Chemical compositions (\%) } \\
\cline { 3 - 7 } & & $\boldsymbol{C}$ & $\boldsymbol{M n}$ & $\boldsymbol{S i}$ & $\boldsymbol{S}$ & $\boldsymbol{P}$ \\
\hline \multirow{2}{*}{$\mathrm{Q} 235$} & $\mathrm{~A}$ & $0.14 \sim 0.22$ & $0.30 \sim 0.65$ & 0.30 & 0.050 & 0.045 \\
\hline
\end{tabular}


In the early development stages of the rods the weldability in different welding angle was mainly studied, plate angle change caused the change for the traditional welding angle, so in order to find a fixed reference coordinates for realizing the regularization of welding angle, the welding angle $\theta$ was shown in Fig .1 in the following paper. The welding angle was positive value when the rods was in the horizontal line below, otherwise the welding angle was negative value.

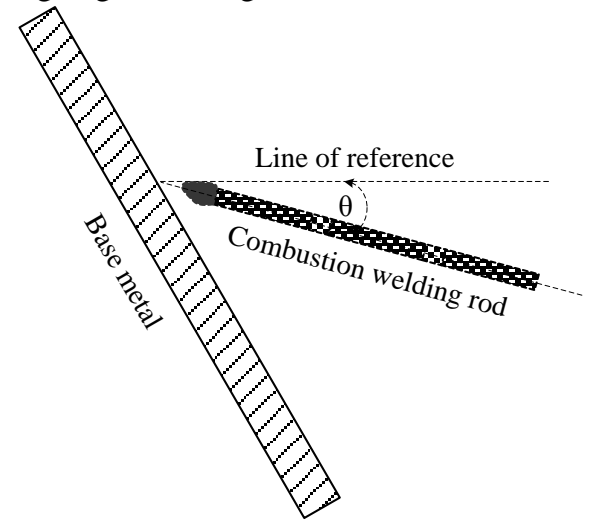

Figure 1. The abridged general view of welding angle

Butt welding that inclination was $60^{\circ}$ was used in experiments, and the welding arc length was $2 \mathrm{~mm} \sim 3 \mathrm{~mm}$. Experimental scheme was shown in table III below.

TABLE III. EXPERIMENTAL SCHEME

\begin{tabular}{|c|c|c|c|c|c|c|}
\hline $\begin{array}{c}\text { Experimental } \\
\text { number }\end{array}$ & $\mathbf{1}$ & $\mathbf{2}$ & $\mathbf{3}$ & $\mathbf{4}$ & $\mathbf{5}$ & $\mathbf{6}$ \\
\hline $\begin{array}{c}\text { Welding } \\
\text { angle/ } \theta\end{array}$ & -45 & -30 & 0 & 30 & 45 & 55 \\
\hline
\end{tabular}

Cladding ratio and depth of fusion for weldment were measured after the experiment, the weldment was processed into standard mechanical properties testing specimen according to GB/T2649-1989, the corresponding mechanical properties were tested, and the relation curves were draw.

\section{RESULTS AND DISCUSSION}

The metal that not cladding on metal surface but mixed into the molten slag after weld was collected, and the mass of which was weighed respectively as shown in table IV below.

TABLE IV. The RunNing OfF OF Fusing Weld Metal

\begin{tabular}{|c|c|c|c|c|c|c|}
\hline $\begin{array}{c}\text { Experimental } \\
\text { number }\end{array}$ & $\mathbf{1}$ & $\mathbf{2}$ & $\mathbf{3}$ & $\mathbf{4}$ & $\mathbf{5}$ & $\mathbf{6}$ \\
\hline Loss metal /g & 8.32 & 6.63 & 4.26 & 2.78 & 5.83 & 16.25 \\
\hline
\end{tabular}

\section{A. The Influence on Cladding Ratio}

According to the measured values in table IV and calculated values by the definition of cladding rate, the relationship curve between the cladding rate and welding angle was shown in Fig .2, by which we could observe that the cladding ratio was highest when the welding angle was about $30^{\circ}$ and the welding effect was best. And the welding effect was very poor when the welding angle was $-45^{\circ}$ and large burnthrough area present to the base metal, the reason of which mainly include two aspects, on the one hand, the blow force direction of welding arc same with the molten pool flow drip direction, so the molten pool drip was greatly promoted, which leading to the loss of metal is heavy; on the other hand, As a result of the molten pool drip, there was no molten pool covered at the surface of the base metal, which resulting in welding arc heating base metal surface directly, then leading to base metal was burnt through, actually the loss metal collected at this time not only including self-propagating hightemperature synthesis reaction of combustion rods, but also including the quality of the melted base metal. Besides, we could observe in experiment that there were remains a large number of cladding metal at the base metal surface even in this welding angle, which showed that the molten solder of the combustion rods reaction was in good wettability with base metal, and the wettability of molten solder plays a more important role compared to the welding arc blow force in the vertical position welding; Welding angle in $-30^{\circ}$ was similar with $-45^{\circ}$, the difference was that the base metal burning through decreased significantly and the cladding ratio improved obviously for welding angle in $-30^{\circ}$, the main reason was that the rods was perpendicular to the surface of base metal, which lead to the acceleration for the molten pool drip decreased significantly; Compare cladding ratio value of the $0^{\circ}$ and $30^{\circ}$ of we could find that the effect of welding arc blow force in boosting the cladding ratio and improve welding effect were still quite significantly, and we could conclude that the best welding angle should be between $25^{\circ}$ to $35^{\circ}$; Cladding ratio was low when the welding angle was $45^{\circ}$, the reason that the loss of weld metal was heavy was mainly due to the thermal efficiency of welding arc for the base metal was decreased, which leading to the heating area being enlarged and heat input of the welding area being reduced, as a result, the wettability of molten solder was reduced and couldn't adhere to the base metal surface.

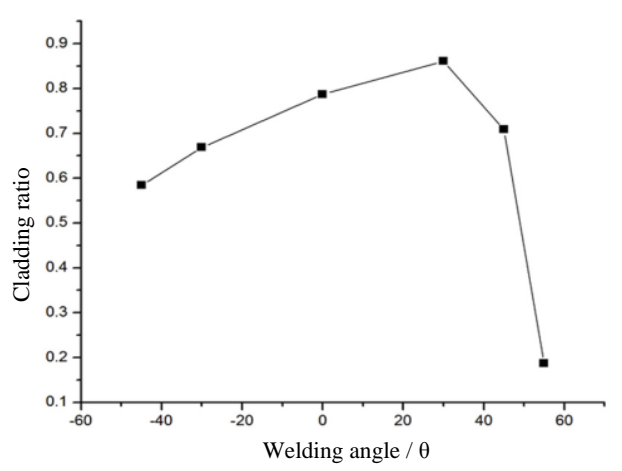

Figure 2. The relation between inclination of welding rods and the ratio of adnexed metal

\section{B. The Influence on The Depth of Fusion}

Depth of fusion for each weldment was taken measure by cutting weldment transversely and the relation curve for welding angle and depth of fusion was drawn as shown in Fig .3, we could found that the forming (not burnthrough) 
part of the weld joints was by and large completely fusion to achieve basic shape on the back of the base metal when the welding Angle was between $45^{\circ}$ to $30^{\circ}$, namely the depth of fusion of base metal basic remains the same; when welding angle was greater than $30^{\circ}$, the depth of base metal decreases rapidly until no connection effective with the increase of welding angle. The reasons were that the heat input of combustion rods for the parent metal $(\delta=$ $3 \mathrm{~mm}$ ) was in surplus when welding angle was less than $30^{\circ}$, therefore, with the increase of welding angle, the heat input for the base metal was reduced, but the welding heat input had declined still enough to complete penetration for base metal, therefore, the influence of welding angle was small for depth of fusion, then we can conclude that the welding effect was best when welding angle was $30^{\circ}$ and the welding heat input as much as the critical value of the base metal penetration. When welding angle was greater than $30^{\circ}$ and continue to increase, due to the decrease of the welding heat input, the base metal penetration Wouldn't occur, and the corresponding relationship between base metal penetration and welding heat input (welding angle) was very sensitive.

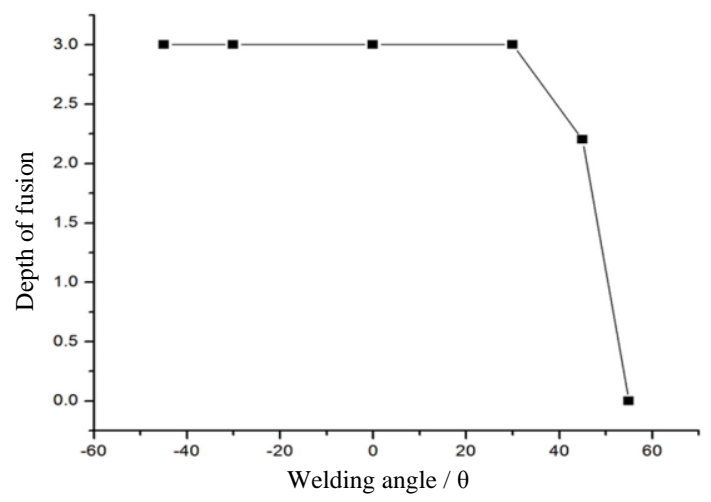

Figure 3. The relation between inclination of welding rods and the depth of fusion

\section{The Influence on Tensile Strength}

Relation curve for welding angle and tensile strength was drawn after mechanics properties test, which was shown in Fig .4. From the figure can we observe that although weldment had large-area burnt through when the welding angle was less than $30^{\circ}$ (less than $-20^{\circ}$ in particular), the tensile properties testing of the molding parts showed that the strength at high value (greater than $400 \mathrm{MPa}$ ) and keeping constant along with the change of welding angle. Due to the decrease of the heat input when welding angle was greater than $30^{\circ}$, the back of the weldment wasn't molding (equivalent to weld defects of incomplete fusion and incomplete penetration), at the same time, the decrease of the welding heat input leads to the overflow time of the gases in the liquid alloy shortened, resulting in internal porosity formation of the weld microstructure, which leads to the mechanical properties of the weldment greatly reduced.

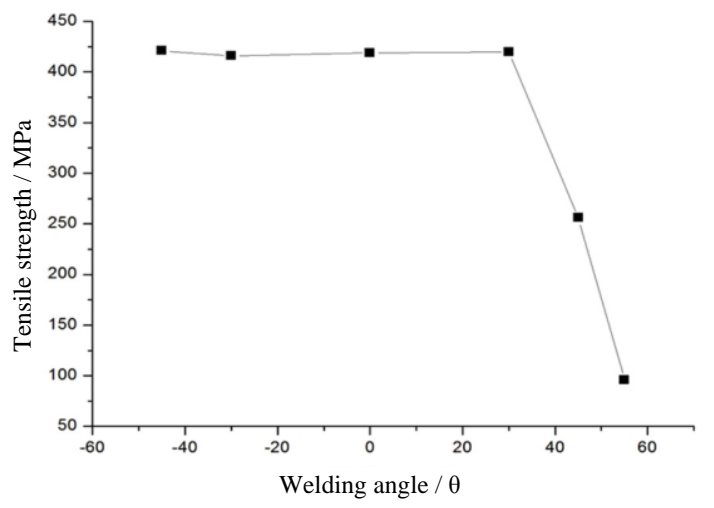

Figure 4. The relation between inclination of welding rods and the tensile strength of joints

\section{The Influence on Microstructure}

The welding joints microstructure under different welding Angle was shown in figure 5.
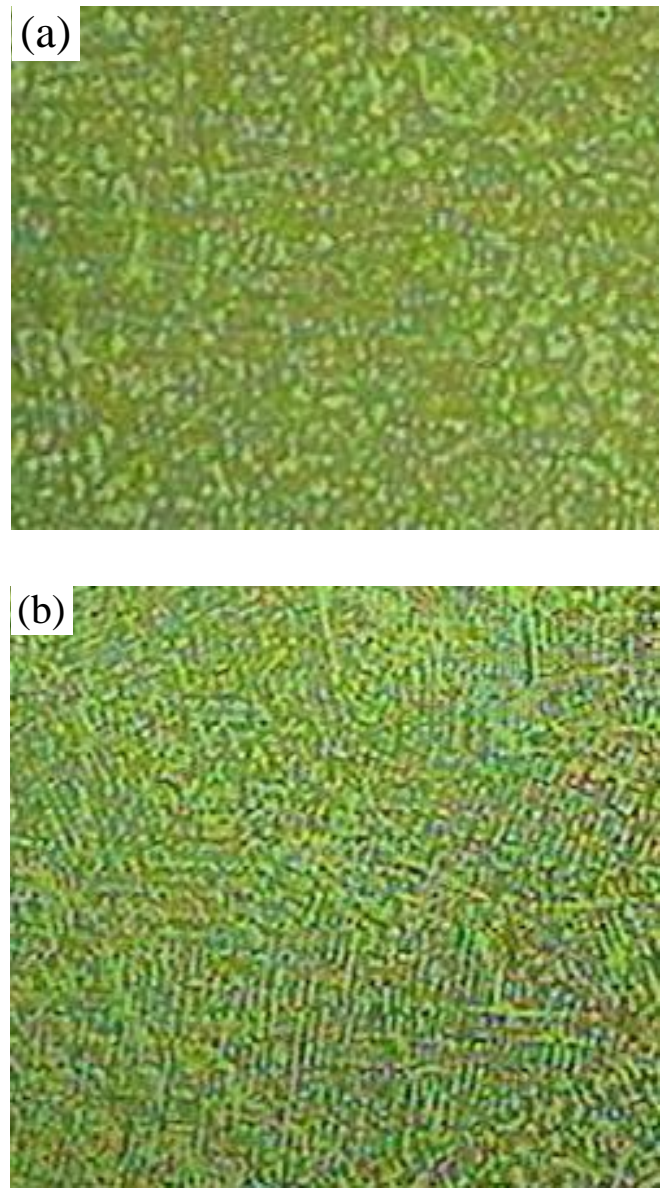


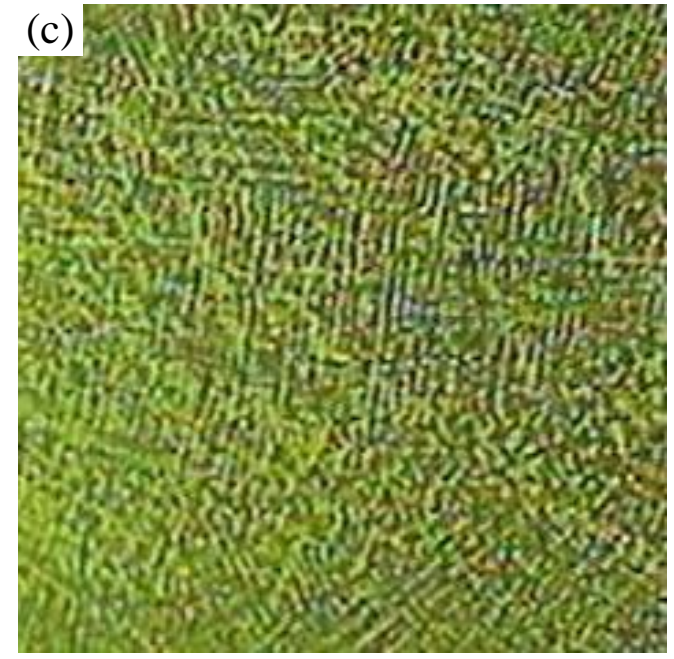

Figure 5. Welding joint microstructure of different when the welding Angle: (a) $-45^{\circ}$; (b) $0^{\circ}$; (c) $45^{\circ}$

By the principle of metal solidification [12], the alloy of the original composition $\mathrm{C} 0$, solid - liquid interface liquid temperature gradient GL and setting rate of $\mathrm{v}$ is the main factor to alloy crystal morphology, therefore in the alloy composition $\mathrm{C} 0$ given conditions, with the decrease of the GL/ v -2, crystal morphology of cellular crystal to equiaxial dendrites, by the above pictures we can observe that the weld joints organization changed from cellular crystal gradually to cellular crystal coexist with cellular dendrites until all were cellular dendrites with welding Angle changes from small to big.

\section{CONCLUSIONS}

(1) The cladding efficiency of the combustion rods and the mechanical properties of joints and the depth of fusion for base metal penetration were all changed along with the change of welding angle by using vertical welding rods whose formula was optimized.

(2) The best welding angle for vertical welding of Q235 steel plate which thickness was $3 \mathrm{~mm}$ was $30^{\circ}$ or so with the optimization formula combustion rods, the base metal was easy to burn through if welding angle was less than $30^{\circ}$, the base metal wasn't easy to form effective connection angle was greater than $30^{\circ}$;

\section{ACKNOWLEDGMENT}

This work was financially supported by the Natural Science Foundation of China (51505491) and the Innovation Program of Naval Aeronautical and Astronautical University (20121009).

\section{REFERENCES}

[1] Zhang Baoyuan, Xin Wentong, Wu Bin and Yao Jungang, "Effect of Al particle size on burning of combustion welding rod," Hot working, vol. 36, Dec. 2007, pp. 47-49, doi:10.3969/j.issn.10013814.2007.19.018.

[2] Liu Haodong, Zhang Long, Xin Wentong, Wang Jianjiang, Wu Yongsheng and Wang Xiaojing, "Ingredient optimization of manual SHS welding rod applicable for vertical welding base on uniform method," Materials Review, vol. 26, Apr. 2012, pp. 12512, doi:10.3969/j.issn.1005-023X.2012.08.032.

[3] Wu Yongsheng, Wang Jianjiang, Xin Wentong, Qu Lifeng and Chen Xueli, "Slag inclusion in joints of vertical weld by plus combustion welding rod," Electric Welding Machine, vol. 44, Feb. 2014, pp. 67-69.

[4] Xin Wentong, Li Zhizun, Li Baofeng, Zhu Bin, Zhang Xuegang and Chen Bo, "Study on quick welding technology under field operations circumstance," Welding, Jan. 2005, pp. 19-21.

[5] Xin Wentong, Ma Shining, Li Zhizun, Li Baofeng and Hu Junzhi, "Technology of manual SHS welding," Hot Working Technology, vol. 36, Dec. 2007, pp. 18-20.

[6] Li Baofeng, Xin Wentong, Li Zhizun and Zhu Haihua, "Study on manual SHS welding based on Q235 steel," Hebei journal of industrial science and technology, vol. 25, July. 2008, pp. 193-197.

[7] Li Jianping, Shi Quan, Gan Maozhi. Theory and application of arming lash-up repair in battlefield[M]. Beijing: weapon industry press, 2000.

[8] Wu Yongsheng, Wang Jianjiang, Xin Wentong, and Qu Lifeng, "Tensile strength and fracture microstructure of Q235 steel joints prepared by manual self-propagating vertical weld," Materials Science and Engineering of Powder Metallurgy, vol. 18, Dec. 2013, pp. 893-898, doi:10.3969/j.issn.1673-0224.2013.06.020.

[9] Zhang Baoyuan, Xin Wentong, Li Zhizun, "Analysis on properties and microstructure of welded joints by manual SHS welding," Hot Working Technology, vol. 36, Jan. 2007, pp. 16-18, doi:10.3969/j.issn.1001-3814.2007.15.006.

[10] Liu Haodong, Zhang Long, Wang Jianjiang and Wu Yongsheng, "Investigation of Vertical Welding Technics and Discussion on Vertical Welding of Manual SHS Welding," Hot Working Technology, vol. 40, Apr. 2010, pp. 16-20.

[11] Zhu Xiequan. Practical metallic material manual data[M]. Science and technology press, 1993.

[12] Hu Hanqi. The freezing mechanism of metal[M]. Beijing: China machine press, 2000,10 . 